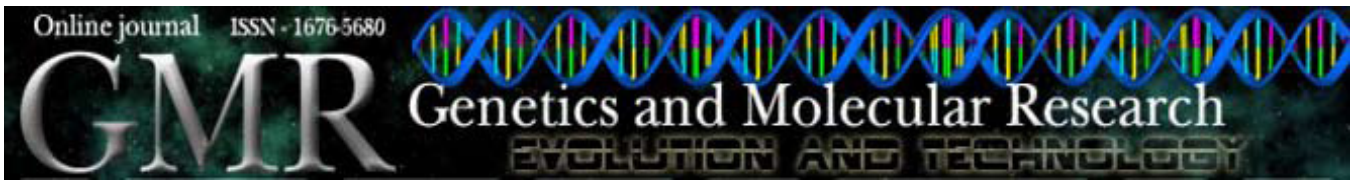

\title{
Spermatogenesis and karyotypes of three species of water striders (Gerridae, Heteroptera)
}

\author{
M.M.U. Castanhole, L.L.V. Pereira, H.V. Souza and M.M. Itoyama \\ Departamento de Biologia, Laboratório de Citogenética e Molecular de Insetos, \\ Instituto de Biociências, Letras e Ciências Exatas, \\ Universidade Estadual Paulista Júlio de Mesquita Filho, \\ São José do Rio Preto, SP, Brasil \\ Corresponding author: M.M. Itoyama \\ E-mail: mary@ibilce.unesp.br
}

Genet. Mol. Res. 9 (3): 1343-1356 (2010)

Received March 18, 2010

Accepted May 14, 2010

Published July 13, 2010

DOI 10.4238/vol9-3gmr841

\begin{abstract}
Although they are of economic importance, there have been few cytogenetic studies of the Gerridae (Heteroptera) in Brazil. We examined spermatogenesis (meiosis and spermiogenesis) and nucleolar behavior in three species of the family Gerridae. Brachymetra albinerva and Halobatopsis platensis were found to have a chromosome complement of $2 \mathrm{n}=25(24 \mathrm{~A}+\mathrm{X} 0)$ and Cylindrostethus palmaris $2 \mathrm{n}=$ $29(28 \mathrm{~A}+\mathrm{X} 0)$ chromosomes. Fifteen individuals of these species were collected from the reservoir of São José do Rio Preto, SP, using screens and were transported in pots containing water to the laboratory, where cytogenetic preparations were made. The polyploidy nuclei are formed by several heteropyknotic regions; cells in meiotic prophase have a heteropyknotic region that is probably the sex chromosome, and the chromosomes from chiasmata. The spermatids are rounded and have a heteropyknotic region at the periphery of the nucleus; the sperm head is small, with a long tail. Silver impregnation of meiotic cells showed one or more disorganized bodies around the perichromosomal sheath. The round spermatids had two bodies next to each other, but these were elongated; one of the bodies remained in the head and the other migrated to the initial part of the tail at the end of spermagenesis, when the staining was no longer evident. The meiotic cells appear during
\end{abstract}


spermatogenesis and have very similar silver-impregnation patterns in different species of Heteroptera.

Key words: Brachymetra; Chiasmata; Cylindrostethus; Halobatopsis; Holocentric chromosomes; Meiosis

\section{INTRODUCTION}

Brachymetra albinerva, Cylindrostethus palmaris and Halobatopsis platensis are insects belonging to the family Gerridae (Heteroptera) and are known as water striders, as they move over water using both the middle and posterior legs. They live on the surface of ponds, slow streams, swamps, and other quiet waters, and can move very quickly, up to $1.5 \mathrm{~m} / \mathrm{s}$. The length of these insects is quite variable, from 1.6 to $36 \mathrm{~mm}$. All have long legs and almost round body. They have an insectivorous diet, feeding on small organisms that may fall on the water. Their eggs are deposited on floating objects (Borror and Delong, 1988).

This family is characterized by having an $\mathrm{X} 0$ sex chromosome system, represented by a metaphasic ring chromosome, and the absence of m-chromosomes. They also show holocentric chromosomes, pre-reductional division of autosomes and post-reductional division of sex chromosomes in meiosis. The modal chromosome number is $21(20 \mathrm{~A}+\mathrm{X} 0)$ or $23(22 \mathrm{~A}+\mathrm{X} 0)$ (Ueshima, 1979; Castanhole et al., 2008).

Cytogenetic data for the Gerridae are extremely rare, as well as the description of nucleolar behavior in Heteroptera. The data described in the literature, for example, show that Spartocera fusca and Carlisis wahbergi (Coreidae, Heteroptera) have a semi-persistent nucleolus during meiosis (Cattani and Papeschi, 2004). In Acanthocoris sordidus (Coreidae) and Coptosoma punctissimum (Plataspidae, Heteroptera), the nucleoli are observed in the metaphase plate of primary and secondary spermatocytes (Yoshida, 1947, 1950; Fossey and Liebenberg, 1995), while in Eubule sculpta (Coreidae), the nucleolus is present up to telophase I, located inside the groups of segregating chromosomes (Colombo and Bidau, 1985). In Nysius californicus (Lygaeidae, Heteroptera) and Antitheuchus tripterus (Pentatomidae, Heteroptera) (Souza et al., 2007a,b), silver staining was observed around the perichromosomal sheath, and in Limnogonus aduncus (Gerridae, Heteroptera), the nucleolar organizer regions (NORs) showed positive silver staining (Castanhole et al., 2008; Castanhole, 2009). The data relating to the behavior of cells, after silver impregnation during spermiogenesis, are also extremely rare. For example, in N. californicus (Souza et al., 2007a) there is still silver staining of the periphery of the nuclear envelope in round spermatids and in the back of the head during elongation (Souza et al., 2007b). In A. tripterus, the presence of the silver-impregnated material is variable in the different lobes during spermiogenesis, leading to the conclusion that silver-staining pattern differs between them (Souza et al., 2007b).

Besides all the features mentioned above, aquatic Heteroptera are also very important economically because they can be used for bio-monitoring air pollution due to heavy metals (Steinnes, 1989). Many aquatic invertebrates can accumulate cadmium and other heavy metals because they are relatively insensitive to these substances (Spehar et al., 1978). Despite the importance of these organisms, they have been little used as bioindicators because they are not easily collected in large enough quantities and very experienced taxonomists are needed for identification (Nummelin et al., 1997). However, there are other advantages; for example, despite having wings, they do not disperse over long distances (Fairbairn, 1986). According to 
Nummelin et al. (1997), it seems that there is a tendency for females to have a greater quantity of heavy metals, which is due to their greater need for energy to produce eggs.

Due to their economic importance, the small number of cytogenetic studies, and several cytogenetic features, our intent was to examine spermatogenesis (meiosis and spermiogenesis) and nucleolar behavior in three species of the family Gerridae (Heteroptera).

\section{MATERIAL AND METHODS}

About 15 samples of Brachymetra albinerva (Amyot and Serville, 1843), Cylindrostethus Palmaris (Drake and Harris, 1934) and Halobatopsis platensis (Berg, 1879) (Gerridae, Heteroptera) were collected in the reservoir of São José do Rio Preto city (20 47'32" S, 49 21'37” W), SP, and region, with the aid of screens, and transported in pots containing water to the Laboratory of Cytogenetics and Molecular of Insects (LACIMI), UNESP/IBILCE. They were separated by gender, fixed in methanol:acetic acid (3:1), and kept in the refrigerator until the preparation of slides by crushing in lacto-acetic orcein (10 individuals) and silver impregnation (15 individuals) according to Howell and Black (1980). Slides were analyzed with a Zeiss microscope, AXIOSKOP 2, and the best images were captured using the Digital Image Processing AXIONVISION 3.1 software (Zeiss).

\section{RESULTS}

The analysis of the testes of B. albinerva, C. palmaris and H. platensis (Heteroptera, Gerridae) showed that they are surrounded by a transparent membrane, formed by two elongated lobes and located in the posterior region of the abdomen.

Cytogenetic analysis demonstrated that the diploid chromosome complement of B.albinerva and $H$. platensis is $2 \mathrm{n}=25(24 \mathrm{~A}+\mathrm{X} 0)$ and of $C$. palmaris is $2 \mathrm{n}=29(28 \mathrm{~A}+\mathrm{X} 0)$ chromosomes. All species examined showed the X0 sex chromosome system. In the cytogenetic analysis of the testes of all species, the lobes were identified and analyzed separately by both the lacto-acetic orcein technique and silver impregnation. Because the meiotic behavior and spermiogenesis were similar between lobes and between species, data are presented together.

\section{Meiotic behavior and spermiogenesis}

The nuclei of polyploid nutrient cells of B. albinerva, C. palmaris and H. platensis were large and contained several small heteropyknotic regions, evenly distributed throughout the cell (Figure 1a). In Heteroptera, the process of spermiogenesis occurs within the spermatogonial cysts, and these cells possess heteropyknotic chromatin in many regions, as can be seen in Figure 1b. In early prophase I (leptotene), cells of the three species have decondensed chromatin and one or two obvious heteropyknotic regions, which are close or separated and of different sizes (Figure 1c, d); this can be observed throughout prophase I (Figures 1d-h and 2a, b). In the beginning, during chromatin condensation, it is possible to observe the terminals and/or interstitial chiasmata (Figure 2a) and the low frequency in these species. We can also see that during the process of condensation, the chromosomes of B. albinerva and H. platensis behave in a similar fashion, although differing from C. palmaris because its chromosomes do not have a defined morphology and, moreover, show chromosome associations (Figure $1 \mathrm{~g}$ ). Another phenomenon observed was that during diplotene, the cells of $C$. palmaris are double the size of those of B. albinerva and H. platensis. 

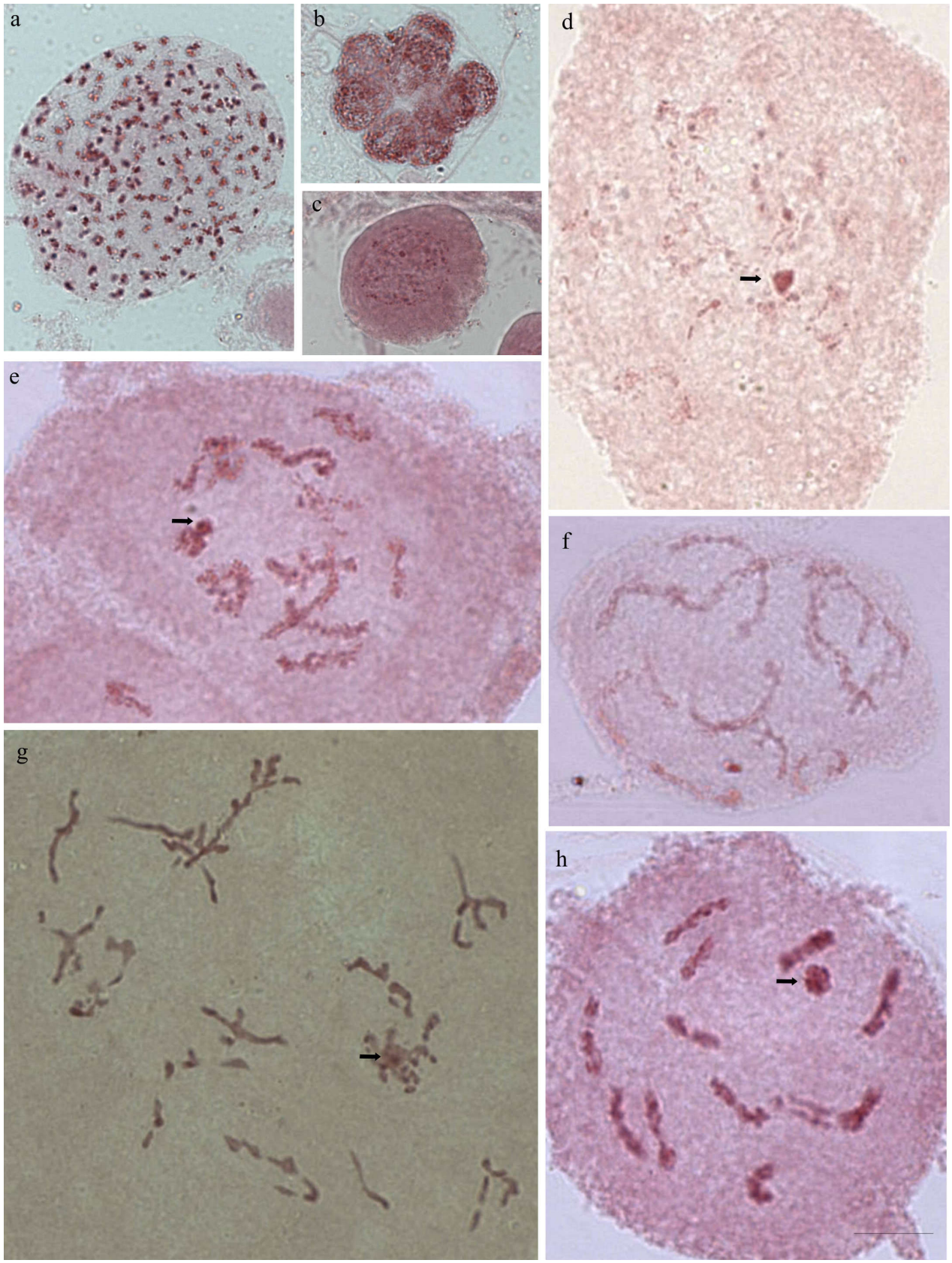

Figure 1. Cells of the seminiferous tubules of adult males of Brachymetra albinerva (a, b, c, f), Cylindrostethus palmaris $(\mathrm{g})$ and Halobatopsis platensis $(\mathrm{d}, \mathrm{e}, \mathrm{h})$ stained with lacto-acetic orcein. a) Polyploid nuclei with multiple heteropyknotic bodies; b) spermatogonial cyst; c, d) prophases in early stage (leptotene-zygotene), and the region more heteropyknotic is probably the sex chromosome (d, arrow); e, f) prophases in intermediate stage (pachytene), showing a more heteropyknotic body (e, arrow); g, h) prophases in advanced stage (diplotene-diakinesis), the presence of chiasmata and heteropyknotic body, arrows. Bar: $10 \mu \mathrm{M}$. 

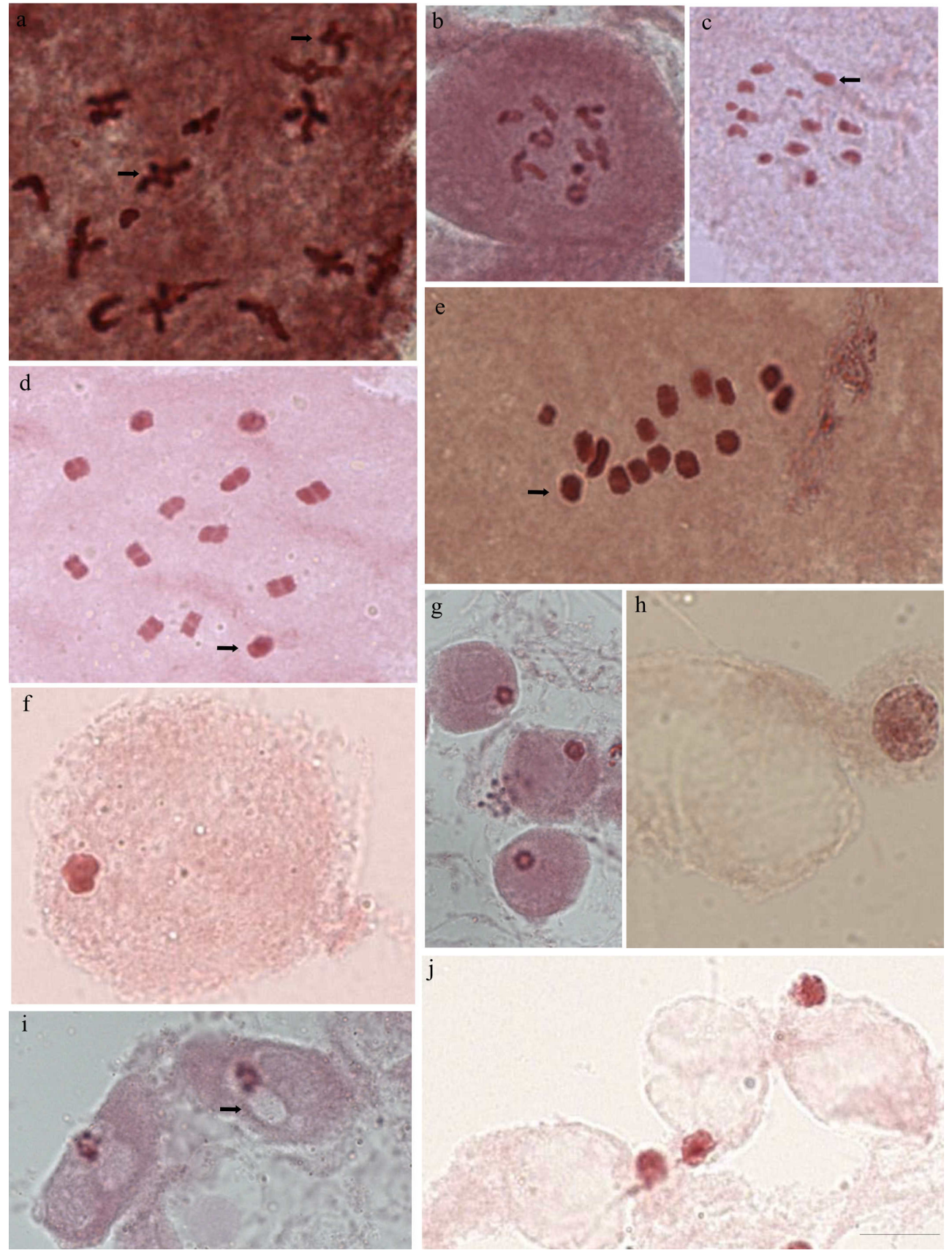

Figure 2. Cells of the seminiferous tubules of adult males of Brachymetra albinerva (b, c, g, i), Cylindrostethus palmaris $(\mathrm{a}, \mathrm{e}, \mathrm{h})$ and Halobatopsis platensis $(\mathrm{d}, \mathrm{f}, \mathrm{j})$ stained with lacto-acetic orcein. $\mathrm{a}, \mathrm{b})$ Diakinesis showing terminal and interstitial chiasmata (arrows) and chromosome associations; c, d) metaphases with 25 chromosomes $(24 \mathrm{~A}+\mathrm{X} 0)$ (sex chromosome, X, arrows); e) metaphase with 29 chromosomes (28A + X0) (sex chromosome, $\mathrm{X}$, arrow); f-h) round spermatids; i, j) spermatid elongation, with the presence of a vesicle (arrow). Bar: $10 \mu \mathrm{M}$. 
At metaphase I (Figure 2b-e), the bivalents appear in the equatorial plate of the cell, where the autosomes form a ring with the sex chromosome at its center or outside the ring, in polar view. From a side view, the chromosomes are all seen aligned.

The process begins with spermiogenesis, where round spermatids and heteropyknotic region shift to the periphery of the nucleus in all species, differing only with respect to size. $H$. platensis cells has eight times more heteropyknotic material than do the other species. During elongation, a small vesicle appears in B. albinerva and a large one in $H$. platensis and C. palmaris (Figure $2 \mathrm{f}-\mathrm{j}$, arrow in Figure $2 \mathrm{i}$ ). With the appearance of this vesicle, the heteropyknotic material moves to one end of the cell and is stretched (Figure $3 a, b$ ), resulting in the heteropyknotic material being moved to the posterior region of the head of the developing spermatids (Figure $3 b$ ). The spermatids in a more advanced stage of development shows the heteropyknotic material as rod-shaped (Figure 3c-i). This material decreases considerably at the end of the process.

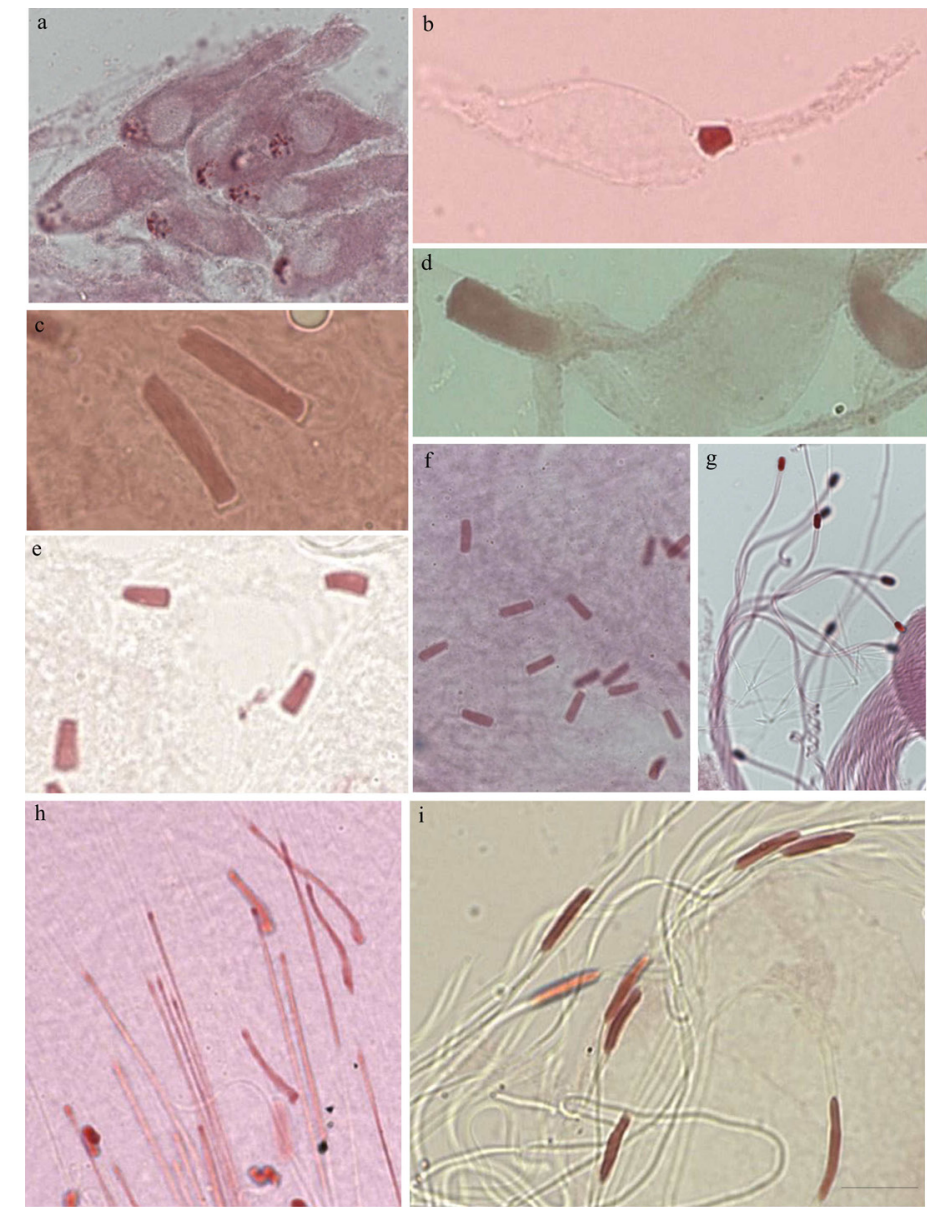

Figure 3. Cells of the seminiferous tubules of adult males of Brachymetra albinerva (a, f, g), Cylindrostethus palmaris (c, d, i) and Halobatopsis platensis $(\mathrm{b}, \mathrm{e}, \mathrm{h}$ ) stained with lacto-acetic orcein. $\mathrm{a}, \mathrm{b})$ Spermatid elongation; c-f) elongated, rod-shaped spermatids (e); g-i) spermatozoa with small head and long tail. Bar: $10 \mu \mathrm{M}$. 


\section{Silver impregnation}

The polyploid nuclei of nutrient cells of B. albinerva and H. platensis have a region that is more silver-impregnated without defined morphology and several small stained bodies (Figure 4a). Cylindrostethus palmaris showed the presence of several small bodies, rounded and distributed throughout the cell (Figure 4b). The initial cells in prophase I (leptotene-pachytene) have a single rounded body that stains strongly and is located at the periphery of the cell (Figure 4c).

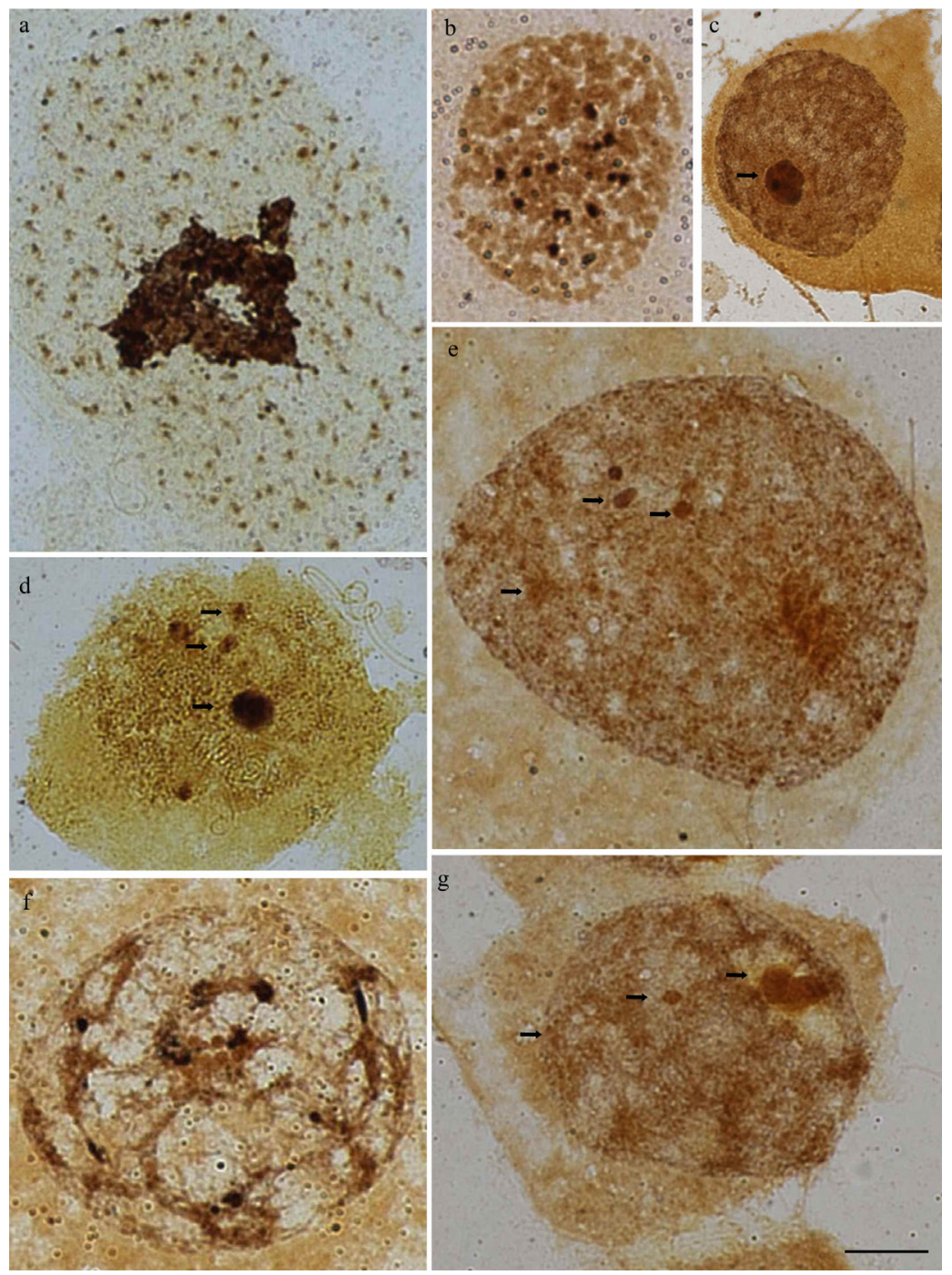

Figure 4. Cells of the seminiferous tubules of adult males of Brachymetra albinerva (c), Cylindrostethus palmaris (b, e, g) and Halobatopsis platensis (a, d, f) silver-impregnated. a) Polyploid nuclei with a large silver-positive region without defined morphology and several smaller ones; b) polyploid nuclei with several bodies, c-e) prophase in early stage (leptotene-zygotene) containing a single body (c, arrow) or with various bodies (d, e, arrows); f, g) prophase in a more advanced stage (pachytene) with various bodies (arrows). Bar: $10 \mu \mathrm{M}$. 
In the process of chromosome condensation, the bodies begin to disintegrate and, in addition to these, other smaller bodies and with less evident staining are observed (Figure 4d, e, g). Silver staining was more evident in $H$. platensis (Figure 4f) until early diplotene (Figure 5a). After the disruption of the body, the material can be observed around the perichromosomal sheath in B. albinerva (Figure 5b) or in the region, possibly being the NOR (Figure 5c, d). At the end of meiosis, the silver-impregnated material is seen until almost the end of telophase in B. albinerva (Figure 5e, f). The silver-positive material in C. palmaris was much more impregnated and bigger in the two cells formed (Figure $5 \mathrm{~g}$ ).
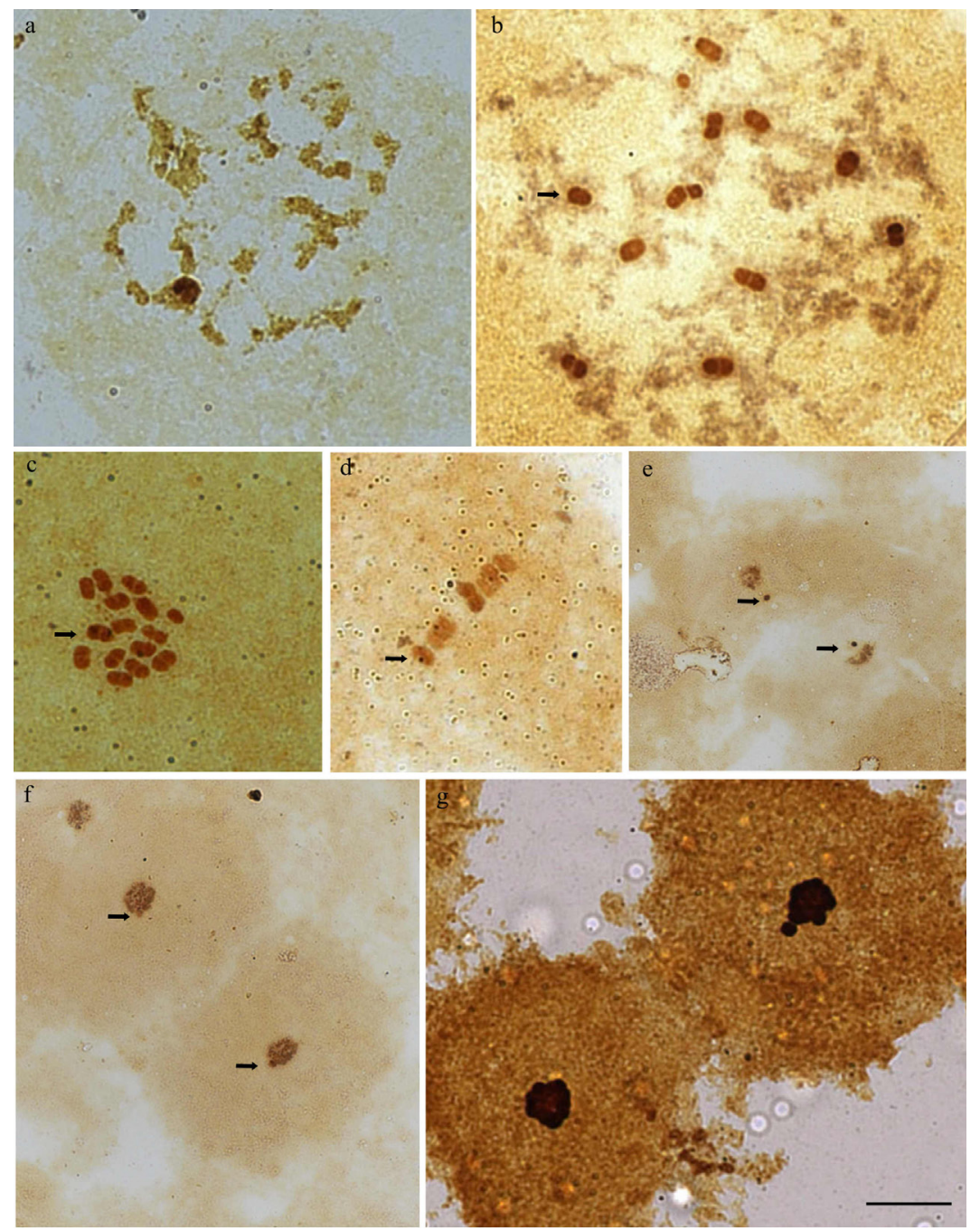

Figure 5. Cells of the seminiferous tubules of adult males of Brachymetra albinerva (b, e, f), Cylindrostethus palmaris (c, g) and Halobatopsis platensis (a, d) silver-impregnated. a) Prophase in final stage (diplotenediakinesis); b, c) metaphases with impregnated material around the perichromosomal sheath (arrows); d) with a possible chromosome marker in the nucleolar organizing region (arrow); e-g) telophase with the presence of two bodies (e, f, arrows) and one body (g). Bar: $10 \mu \mathrm{M}$. 
In spermiogenesis, at the beginning of the round spermatids, there are three silverstaining regions at one of the poles, one round and always isolated and the other two being more elongated and found side by side or overlapping (Figure 6a). With the development of the spermatids, the stained regions begin to separate, where one remains at the same end and the other migrates to the opposite pole (Figure 6b-e). The spermatids of $C$. palmaris were around four times larger than those of $H$. platensis and B. albinerva, but had the same silver impregnation pattern.
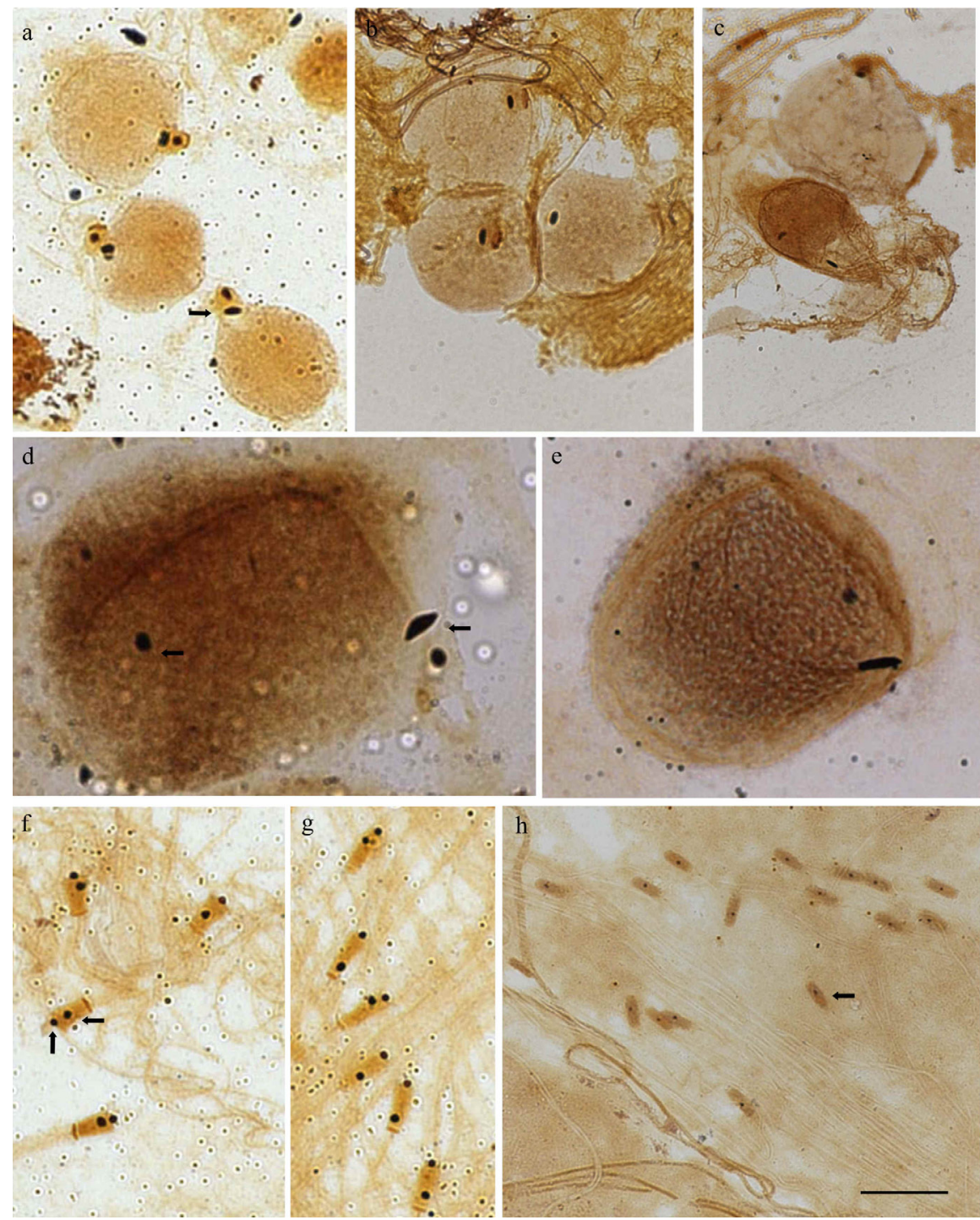

Figure 6. Cells of the seminiferous tubules of adult males of Brachymetra albinerva (b, c, h), Cylindrostethus palmaris $(\mathrm{d}, \mathrm{e})$ and Halobatopsis platensis $(\mathrm{a}, \mathrm{f}, \mathrm{g}$ ) silver-impregnated. c) Round spermatids with staining in the anterior region (arrow); d, e) spermatid elongation with bodies of different morphology (arrow); f-h) rod-shaped spermatids with staining of the anterior and posterior head (f, g, arrows) or in the middle and above the head (h, arrow). Bar: $10 \mu \mathrm{M}$. 
In a more advanced stage of development, spermatids become rod-shaped with the three silverstaining regions distributed at both ends and in between. The stained posterior region is elongated and the other two regions are rounded (Figures $6 \mathrm{f}-\mathrm{h}$ and $7 \mathrm{a}, \mathrm{b}$ ). As they elongate, the stained regions are still visible (Figure 7c, d). Near the end of spermiogenesis, silver impregnation signals are visible only in the head as one stained region only (Figure $7 \mathrm{e}, \mathrm{f}$ ).
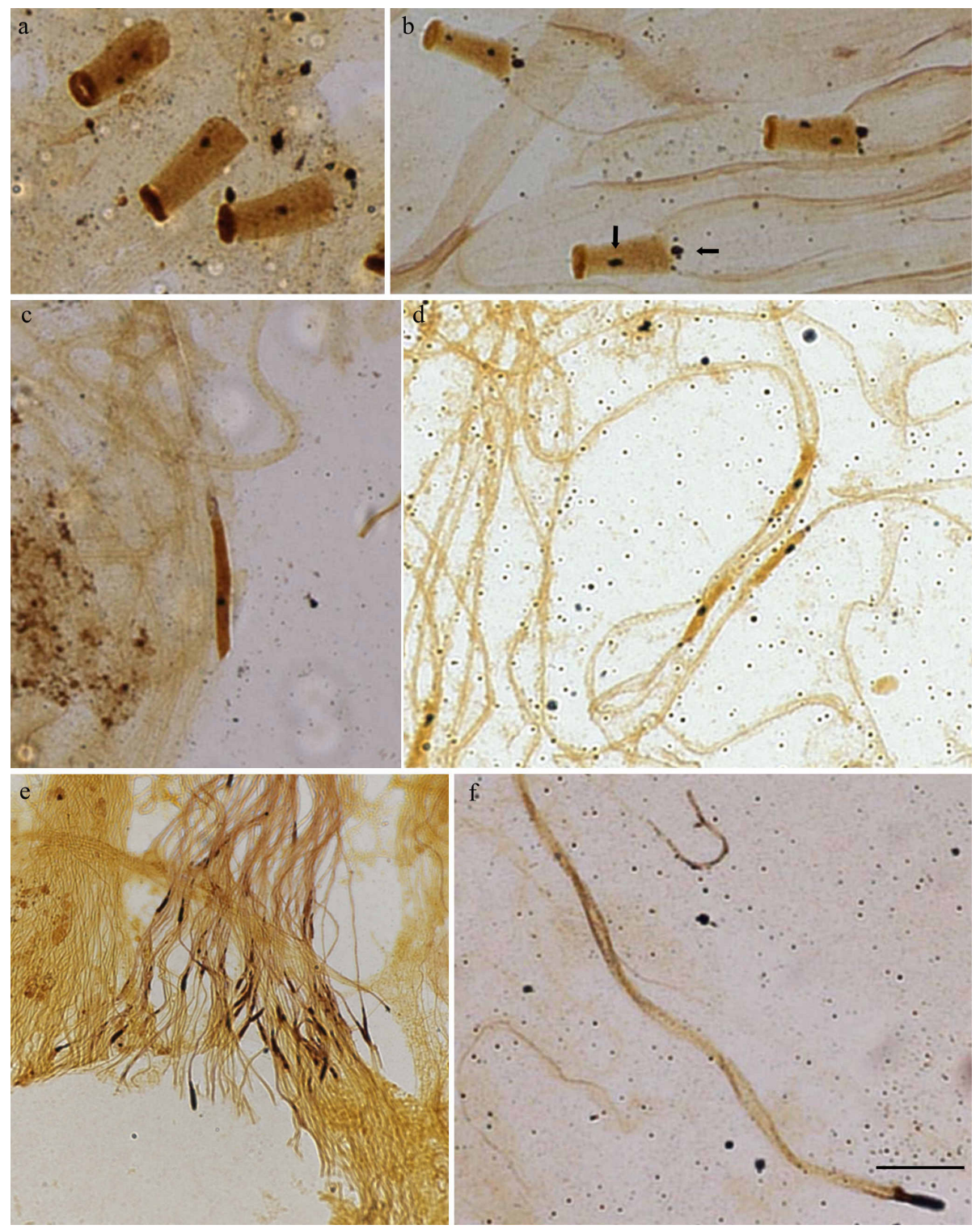

Figure 7. Cells of the seminiferous tubules of adult males of Brachymetra albinerva (c), Cylindrostethus palmaris $(\mathrm{a}, \mathrm{b}, \mathrm{e}, \mathrm{f})$ and Halobatopsis platensis (d) silver-impregnated. a, b) Still in spermatid elongation with two silverstaining regions (arrows); c-f) spermatid elongation. Note that the silver-stained regions are visible until the end of spermiogenesis, mainly in the head. Bar: $10 \mu \mathrm{M}$. 


\section{DISCUSSION}

The polyploid nuclei of nutrient cells of B. albinerva, C. palmaris and H. platensis were found to be similar but showed different heteropyknotic regions. The behavior of these cells is quite variable and can differentiate species of the same family. The species of the Coreidae, examined by Souza et al. (2007c), showed, for example, polyploid nuclei in the interphase stage (with or without heteropyknotic regions) or in division (highly condensed chromosomes). In $A$. tripterus (Pentatomidae, Heteroptera), the polyploid nuclei are formed from several large and small heteropyknotic bodies (Souza et al., 2007b), with the same occurring in N. californicus (Lygaeidae, Heteroptera) (Souza et al., 2007a). With respect to these nuclei, their behavior seems to be particular to each species.

The presence of a heteropyknotic body in meiotic cells in prophase I was observed by several investigators who all referred to it as a condensed sex chromosome (Souza et al., $2007 a, b, c)$. The three species of the Gerridae, analyzed in this study, also showed its presence, confirming the hypothesis that this body is the sex chromosome, since these species have an X0 sex chromosome system.

During meiotic prophase I, the condensation of chromosomes occurs in a homogeneous manner, where the chromosomes always show a well-defined morphology. This could be seen in B. albinerva and H. platensis. The morphology of the chromosomes of $C$. palmaris is quite variable, where they resemble those of Athaumastus haematicus (Coreidae) (Souza et al., 2007c), but there was no reason to conclude that the pattern was different. Considering this different pattern, there was some difficulty in determining the presence of a chiasma.

With regard to other characteristics such as the presence of holocentric chromosomes, chiasmatic meiosis and sex chromosome system X0, all species showed similar characteristics. They differed only with respect to the number of autosomes, which was 24 (B. albinerva and H. platensis) and 28 (C. palmaris), higher than the default number in families reported in the literature, that is 20 or 22 autosomes (Ueshima, 1979).

As the Heteroptera have holocentric chromosomes, the retention of chromosome pieces generated by fragmentation is possible, thus allowing the extension of the number of chromosomes, or if fusion occurs, this could lead to a reduction in chromosome number. As the default number in the Gerridae is 20 or 22 chromosomes, it is likely that there were chromosome breaks in the species examined, since most show a smaller number of chromosomes. However, we need to confirm this, for example, by quantifying the DNA content of these species and comparing it to that of species with 20 or 22 chromosomes, to make sure that there actually was only one chromosomal rearrangement.

Cytogenetically, the Heteroptera have very similar characteristics, with no conditions to distinguish the terrestrial from aquatics species. Maybe this is only possible if you look at spermatid elongation, because the water insects acquire a rod shape and the terrestrial insects acquire an elliptical shape. Although few species have been assessed so far, even this feature could still be used.

The chromosomes of Heteroptera are small and highly condensed, making their analysis difficult, mainly chromosome banding. Attempts related to silver impregnation or in situ hybridization were not satisfactory, perhaps because of these characteristics. Perhaps, this also explains the small number of species for which meiotic behavior and 
NOR localization have been described. The few species with such information include Asellus aquaticus (Isopoda) where Ag-NOR bodies are seen during the entire process of spermatogenesis (Di Castro et al., 1983), Callicrania seoane (Orthoptera) regarding interkinesis to pro-metaphase II (Santos et al., 1987), and Triatoma infestans and T. sordida (Heteroptera, Reduviidae) where silver staining is present up to metaphase I (Tavares and Azeredo-Oliveira, 1997). Finally, in C. wahlbergi (Heteroptera, Coreidae), semi-nucleolar persistence (presence of nucleolar bodies during metaphases) was observed until metaphase II (Fossey and Liebenberg, 1995), while in A. sordidus (Heteroptera, Coreidae) and C. punctissimum (Heteroptera, Plataspidae), the nucleoli were detected in metaphase plates of primary and secondary spermatocytes (Yoshida, 1947). In the Pentatomidae species $N$. californicus and A. tripterus, the silver-staining region was observed in the perichromosomal sheath (Souza et al., 2007a,b).

Regarding the description of NOR in the Belostomatidae, they have been found in the telomeric region of the sex chromosomes X and Y (Belostoma oxyurum and B. micantulum), or in an autosomal telomeric region (B. elegans) (Papeschi and Bressa, 2002). In the Coreidae, one NOR was found in the interstitial region of the largest autosomal chromosome in Pachylis argentinus (Papeschi et al., 2003) and the telomeric region of an autosomal chromosome in $C$. wahlbergi (Fossey and Liebenberg, 1995) and S. fusca (Cattani and Papeschi, 2004). In the Pentatomidae, a single NOR was detected in the telomeric region of an autosomal chromosome in Edessa meditabunda (Rebagliati et al., 2003), the middle of the largest autosomal chromosome in Nezara viridula (Camacho et al., 1985; Papeschi et al., 2003) and the telomeric region of the X chromosome in Graphosoma italicum (González-García et al., 1996). In the Gerridae, L. aduncus, one NOR was observed in an autosomal chromosome (Castanhole et al., 2008; Castanhole, 2009).

The species analyzed in this study showed a notable perichromosomal sheath similar to that observed by Souza et al. $(2007 \mathrm{a}, \mathrm{b})$ and in some specific regions of some autosomes, suggesting the occurrence of an NOR in that region. The best alternative may be to obtain specific sequences of rDNA of Heteroptera to be able to hybridize with the materials to be evaluated, but due to the small size and high level of condensation, this technique may also be ineffective.

One of the differences between terrestrial and aquatic species during spermiogenesis is the presence of a vesicle in round spermatids in the process of elongation, which is not observed in terrestrial insects [Pentatomidae (Souza et al., 2007b, 2008), Coreidae (Souza et al., 2007c)]. Perhaps this feature is related to the fact that aquatic species need an extra amount (stock) of energy, for locomotion for example, because besides this characteristic, they have a large amount of fat in the abdominal region.

Regarding the method of silver impregnation, there are some doubts about the spermiogenesis process described here: the silver-stained material assumed to be nucleolar proteins could have been cellular structures such as mitochondria and Golgi complex, or it was not certain if the structures analyzed were in the process of elimination or modification, such as the chromatin bodies. Therefore, in further studies, the process of spermiogenesis should be examined by other techniques, for example, transmission electron microscopy, where these structures can be viewed in detail.

\section{ACKNOWLEDGMENTS}

Special thanks go to Dr. Sonia Maria Oliani, Department of Biology, IBILCE/ UNESP, for the opportunity to capture cell images and to Dr. Luis Antônio Alves Costa, 
National Museum of Rio de Janeiro, for the identification of species. Research supported by FUNDUNESP, FAPESP and CAPES.

\section{REFERENCES}

Borror DJ and Delong DM (1988). Introdução ao estudo dos insetos. Edgard Blucher Ltda., São Paulo.

Camacho JPM, Belda J and Cabrero J (1985). Meiotic behaviour on the holocentric chromosomes of Nezara viridula (Insecta, Heteroptera) analyzed by C-banding and silver impregnation. Can. J. Genet. Cytol. 27: 490-497.

Castanhole MMU (2009). Spermatogenesis and nucleolar behavior in males of aquatic Heteroptera (Thesis abstract). Genet. Mol. Res. 8: 816.

Castanhole MM, Pereira LL, Souza HV, Bicudo HE, et al. (2008). Heteropicnotic chromatin and nucleolar activity in meiosis and spermiogenesis of Limnogonus aduncus (Heteroptera, Gerridae): a stained nucleolar organizing region that can serve as a model for studying chromosome behavior. Genet. Mol. Res. 7: 1398-1407.

Cattani MV and Papeschi AG (2004). Nucleolus organizing regions and semi-persistent nucleolus during meiosis in Spartocera fusca (Thunberg) (Coreidae, Heteroptera). Hereditas 140: 105-111.

Colombo P and Bidau C (1985). Estudios cromosómicos en Heterópteros argentinos. I. Los cromosomas meióticos de cinco especies de Coreidae. Physis. Secc. 43: 29-40.

Di Castro M, Prantera G, Cipriani L and Rocchi A (1983). Silver staining analysis of nucleolar-organizer activity during spermatogenesis of Asellus aquaticus (Crustacea, Isopoda). Genetica 60: 163-166.

Fairbairn DJ (1986). Does alary dimorphism imply dispersal dimorphism in the waterstrider, Gerris remigis? Ecol. Entomol. 11: 355-368.

Fossey A and Liebenberg H (1995). Meiosis and nucleolar structures in the stink bug Carlisis wahlbergi Stal (Coreidae: Heteroptera). Cytobios 81: 7-15.

González-Garcia JM, Antonio C, Suja JA and Rufas JS (1996). Meiosis in holocentric chromosomes: kinetic activity is randomly restricted to the chromatid ends of sex univalents in Graphosoma italicum (Heteroptera). Chromosome Res. 4: 124-132.

Howell WM and Black DA (1980). Controlled silver-staining of nucleolus organizer regions with protective colloidal developer: a 1-step method. Experientia 36: 1014-1015.

Nummelin M, Lodenius M and Tulisalo E (1997). Water striders (Heteroptera, Gerridae) as bioindicators of heavy metal pollution. Entomol. Fennica 8: 185-191.

Papeschi AG and Bressa MJ (2002). Cytogenetic studies in Belostomatidae from Argentina. Abstracts of the Second Quadrennial Meeting of the International Heteropteristis Society, St. Petersburg, 46.

Papeschi AG, Mola LM, Bressa MJ, Greizerstein EJ, et al. (2003). Behaviour of ring bivalents in holokinetic systems: alternative sites of spindle attachment in Pachylis argentinus and Nezara viridula (Heteroptera). Chromosome Res. 11: 725-733.

Rebagliati P, Papeschi AG and Mola LM (2003). Meiosis and fluorescent banding in Edessa meditabunda and E. rufomarginata (Heteroptera: Pentatomidae: Edessinae). Eur. J. Entomol. 100: 11-18.

Santos J, Sentis C and Fernandez-Piqueras J (1987). Pattern of nucleolar organizer region activity during male meiosis in Callicrania seoanei (Orthoptera) as analyzed by silver staining: evidences for a possible reactivation in the period between the two meiotic divisions. Genome 29: 516-518.

Souza HV, Bicudo HE and Itoyama MM (2007a). Study of chromosomal and nucleolar aspects in testes of Nysius californicus (Heteroptera: Lygaeidae). Genet. Mol. Res. 6: 33-40.

Souza HV, Bicudo HEMC, Costa LAA and Itoyama MM (2007b). A study of meiosis and spermatogenesis in different testicular lobes of Antiteuchus tripterus (Heteroptera, Pentatomidae). Eur. J. Entomol.104: 353-362.

Souza HV, Arakaki RLM, Dias LN, Murakami AS, et al. (2007c). Cytogenetical aspects of testicular cells in economically important species of Coreidae family (Heteroptera). Cytologia 72: 49-56.

Souza HV, Castanhole MM, Bicudo HE and Itoyama MM (2008). Pattern of silver nitrate-staining during meiosis and spermiogenesis in the testicular lobes of Antiteuchus tripterus (Heteroptera: Pentatomidae). Genet. Mol. Res. 7: 196-206.

Spehar RL, Anderson RL and Fiandt JT (1978). Toxicity and bioaccumulation of cadmium and lead in aquatic invertebrates. Environ. Pollut. 15: 195-208.

Steinnes E (1989). Biomonitors of Air Pollution by Heavy Metals. In: Control and Fate of Atmospheric Heavy Metals (Ottar B and Pacyna J, eds.). Kluwer Academic Publishers, Dordrecht, 321-328.

Tavares MG and Azeredo-Oliveira MTV (1997). Pattern of nucleolar activity during spermatogenesis in triatomines (Heteroptera: Reduviidae) as analyzed by silver staining. Cytobios 89: 93-103.

Ueshima N (1979). Animal cytogenetics, Insecta 6, Hemiptera: Heteroptera. Gebruder Borntraeger, Berlin. 
Yoshida T (1947). Unusual type of the nucleolus observed in a bug, Acanthocoris sordidus. J. Fac. Sci. Hokkaido Univ. (Zool.) 9: 243-249.

Yoshida TH (1950). Remarkable behavior of the nucleolus in meiosis of Acanthocoris sordidus Thumb. (Heteroptera) (in Japanese). Kromosomo 7: 273-282. 